\title{
Article \\ Effect of Ground Electrodes on the Susceptibility to Damage of Customer Premises Equipment (CPE) under Impulse Conditions
}

\author{
Usman Muhammad $^{1}$, Normiza Mohamad Nor ${ }^{1, *(\mathbb{D}}$, Annuar Mohd Ramli ${ }^{2}$ and Nurul Nadia Ahmad ${ }^{1}$ \\ 1 Faculty of Engineering, Multimedia University, Jalan Multimedia, Cyberjaya 63100, Malaysia; \\ 1191402742@student.mmu.edu.my (U.M.); nurulnadia.ahmad@mmu.edu.my (N.N.A.) \\ 2 Fixed Infra Media Lab, Research \& Innovation Development Division, TMRD Sdn. Bhd, \\ TM Innovation Centre, Cyberjaya 63000, Malaysia; annuar@tmrnd.com.my \\ * Correspondence: normiza.nor@mmu.edu.my
}

Citation: Muhammad, U.; Mohamad Nor, N.; Ramli, A.M.; Ahmad, N.N. Effect of Ground Electrodes on the Susceptibility to Damage of Customer Premises Equipment (CPE) under Impulse Conditions. Energies 2022, 15, 1247. https://doi.org/ $10.3390 /$ en15031247

Academic Editor: Issouf Fofana

Received: 27 December 2021

Accepted: 1 February 2022

Published: 8 February 2022

Publisher's Note: MDPI stays neutral with regard to jurisdictional claims in published maps and institutional affiliations.

Copyright: (c) 2022 by the authors Licensee MDPI, Basel, Switzerland. This article is an open access article distributed under the terms and conditions of the Creative Commons Attribution (CC BY) license (https:// creativecommons.org/licenses/by/ $4.0 /)$

\begin{abstract}
One of the requirements for the safe operation of customer premises equipment (CPE) is an adequate grounding system as a means to divert high fault currents to the ground. In this work we report on the results of an experimental study of the impulse characteristics at a charging voltage of $30 \mathrm{kV}$ on the surge protective device connected to 16 earth electrodes and installed at two sites, giving various ground resistance at low voltages, $R_{\mathrm{DC}}$ values. All of these grounding electrodes were installed and tested under the same charging voltage to determine the effectiveness of ground electrodes toward the damage of a modem at the premises. We observed that modems did not experience damage when the ground electrode of the distribution pole (DP) had an RDC below $30 \Omega$ in general and below $46 \Omega$ when ground electrodes installed in low resistivity soil were used. The impulse polarity did not affect the damage susceptibility of the CPE.
\end{abstract}

Keywords: grounding system; customer premises equipment (CPE); damage susceptibility; impulse conditions

\section{Introduction}

A good grounding system is necessary to provide the path for a high magnitude of current to be discharged into the ground and to reduce the voltage rise in the vicinity of the grounding system subjected to high impulse. A good grounding system can be achieved by considering two major parameters: ground electrode and soil resistivity. As generally defined in many standards [1,2], a low ground resistance value $R_{D C}$ is required so that a high current can be effectively discharged to the ground, and the voltage rise can be reduced. In practice, however, it is sometimes challenging to obtain a low resistance value due to a limited availability of ground area, proximity to other facilities (substations, telecommunications poles, and buildings), high soil resistivity in some areas, and more usage of insulated cables, which can no longer be considered as part of grounding systems.

Using an EMTP, Hidaka et al. [3] demonstrated that the protection level for equipment of low voltage equipment with an $\mathrm{R}_{\mathrm{DC}}$ of $40 \Omega$ (with the ground wire) is close to the performance of $30 \Omega$ (without the ground wire). They further reasoned that $30 \Omega$ is adequate for low voltage equipment, as regulated by the local company, but the ground wire can improve the performance to some extent. However, the study [3] was performed for a $6.6 \mathrm{kV}$ distribution line and by the computational method.

Due to a limited study presence correlating the effectiveness of grounding systems with the performance of a telecommunication modem, and by experimental approach, this paper investigates the relationship of $R_{D C}$ with the voltage level of a modem that causes damage to telecommunication systems. Further, experimental work on the performance of the modem in a real application with various ground electrodes and its corresponding $\mathrm{R}_{\mathrm{DC}}$ has not been extensively presented before. Modems are normally tested and specified as in ITU-T K.21: Series K [4]; however, these standard methods of testing do not provide 
the condition in situ. Though it is recommended to have a low ground resistance value for the grounding facility, it can be challenging and difficult to achieve the required low resistance value. Furthermore, the suggested values proposed in the standard to be used as the grounding facility's requirements, as a basis used in real engineering practice, (i.e., below $10 \Omega$ ) may not be realized in high resistivity soil. Commercial modems are designed and developed to pass the compliance tests performed in the laboratory. However, at real sites (customer premises), modems can be susceptible to factors, such as the various grounding at the DP and customer premises, resistive coupling [5], and effectiveness of the surge protective device.

This paper is a continuation of Ramli et al. [5]. In their studies, the test setup was carried out at a field site, where the source of lightning was from real events. Various magnitudes and responses of impulse conditions were seen, necessitating a longer period of study to ensure that adequate data were obtained for analysis. Furthermore, ground electrodes cannot easily be varied since the testing was carried out at the designated site of a telecommunication station where the areas were limited only to the specific site. For this reason, this paper attempted to determine the effective $R_{D C}$ value that was suitable and considered acceptable to be used along with the modem. This study would be useful to manufacturers with regards to enhancing the withstand levels of the modem and establishing whether there is a need to improve the grounding systems at the distribution box (DP) pole and at the customer's premises. This paper focuses on the effect of the ground electrodes at the DP, where the effective $R_{D C}$ values from this study can be applied as a basis of grounding systems for modems. By having various ground electrodes at the DP, the susceptibility of the modem to various ground resistance values $R_{D C}$ to the transient can be determined. Impulse tests were carried out on various ground electrodes that were installed at two sites and connected to the modem, where the ground resistance value $R_{D C}$ that will not cause damage to the modem was determined. It was revealed that a modem was susceptible to damage by the ground electrodes at an $R_{D C}$ value of above $30 \Omega$ in general and above $46 \Omega$ for the ground electrodes installed in low resistivity soil.

Impulse polarity has been known to cause different performances of grounding systems [6,7], and many pieces of electrical equipment [8,9] with higher negative impulse voltage levels have caused a breakdown of the soil. Due to the complexities of the electric field distribution, physical shapes of electrical equipment, as well as various grain sizes, soil density, inhomogeneity of soil resistivity, and soil composition, the impulse polarity effect may not be that observable in some studies [6,7], a fact which leads to inconsistent results from one study to another. Due to differences in the findings of impulse polarity effects in several studies, it is important to determine the voltage level that causes damage to the modems when subjected to both impulse polarities. Ultimately, in this paper, impulse polarity was found to have no effect on the resistance of CPE toward damage. This paper contributes to the proposed ground resistance value that is suitable to be used at the DP, which will not cause damage to the CPE.

\section{Test Arrangement}

\subsection{Impulse Test Equipment}

Figure 1 shows the test setup used, where a combination impulse generator that can generate $1.2 / 50 \mu \mathrm{s}$ from the magnitudes of $30 \mathrm{kV}$ to $300 \mathrm{kV}$. A current rating of $10 \mathrm{kA}$ was used, which was injected into the distribution pole (DP) box. The cable that entered the DP box was the paired cable, and the one that went out from the box was the drop wire; these cables were based on ANSI/TIA/EIA 568-B [10]. Inside the DP box, a gas surge arrester was used to divert the high current to the ground during overvoltages; the gas surge arrester was connected to several ground electrodes, defined as ground electrodes for the DP. The details of its configurations and ground resistance $\mathrm{R}_{\mathrm{DC}}$ values are listed in Section 2.2. A voltage divider with a ratio of 3890:1 and a current transformer 1 of $0.01 \mathrm{~V} / \mathrm{A}$ were used for the measurement of the applied voltage and current of the ground electrode. The signals of voltage and current were obtained with a digital storage oscilloscope (DSO). 


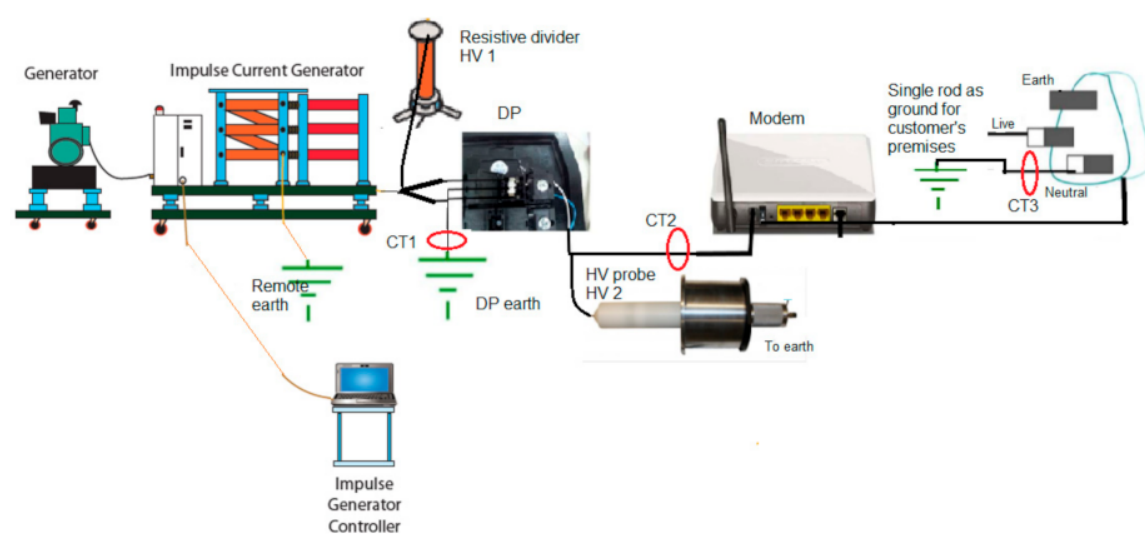

Figure 1. Test arrangement used in the study.

From the DP, via drop wires, the DPwas connected to the modem where the voltage and current of the modem were measured with divider, HV2 with a ratio of 1000:1 and a current transformer with $0.1 \mathrm{~V} / \mathrm{A}$ sensitivity, where both measurements were captured by the DSO. In order to replicate the condition and connection of the modem at the premises, a diesel generator was used to set the modem to ' $\mathrm{ON}^{\prime}$ mode, and the neutral part of the power adapter was connected to the ground electrode, which in this case was a single rod electrode. The power adapter used for the modem in this work was the earth pin made of plastic to ensure any high voltage or current would be discharged to the ground electrode of the power adapter via a neutral cable, which was a typical TT ground systems used in Malaysia, as outlined in [11].

Current transformer 3 measured the current that flowed to the ground through the utility's ground installation. Figure 1 shows the test setup used in the study. Because we expected various modems to have different susceptibility levels toward lightning, one type/brand of modem was used throughout the tests, and the modem was replaced with a new one after every test was carried out. The lowest charging voltage that was capable of generating this impulse generator was $30 \mathrm{kV}$ injected into the paired cables before the DP. It should be noted that there was no direct connection from the ground of one equipment piece to another (i.e., the ground for the DP was not connected to the ground of the power adapter and remote earth).

\subsection{Testing Sites}

Ground electrodes were installed at two different sites. Wenner method was applied to determine soil resistivity, and CDEGS was used to interpret the soil into 2-layer soil models. Table 1 summarizes the soil resistivity profiles for these two sites, in which site 2 had lower soil resistivity than site 3 . Site 2 was split into $2 \mathrm{a}$ and $2 \mathrm{~b}$ where two groups of electrodes were placed $50 \mathrm{~m}$ apart from each other.

Table 1. Soil resistivity profiles of testing sites.

\begin{tabular}{ccccc}
\hline Site & $\begin{array}{c}\text { Upper Layer } \\
\text { Soil Resistivity }\end{array}$ & $\begin{array}{c}\text { Lower Layer } \\
\text { Soil Resistivity }\end{array}$ & $\begin{array}{c}\text { Height of Upper } \\
\text { Layer }(\mathbf{m})\end{array}$ & $\begin{array}{c}\text { Height of Lower } \\
\text { Layer }(\mathbf{m})\end{array}$ \\
\hline 1 & 84.96 & 892 & 12.54 & $\mathrm{Inf}$ \\
$2 \mathrm{a}$ and $2 \mathrm{~b}$ & 78.41 & 126.36 & 1.84 & $\mathrm{Inf}$ \\
\hline
\end{tabular}

\subsection{Ground Electrodes}

Sixteen ground electrodes under tests were used and installed at sites 1, 2a, and 2b, where these ground electrodes were labelled DP earth. Table 2 summarizes the ground electrodes used, in which 6 of these configurations were similar to that presented in [5], with the rod electrode configuration being as follows: (a) at $1.5 \mathrm{~m}$ length, with $16 \mathrm{~mm}$ diameter rod; (b) the rod electrode (a) connected by copper plate, of $2 \mathrm{~cm}$ width, 
$0.2 \mathrm{~mm}$ thickness, and $3 \mathrm{~m}$ length; and (c) was the rod electrode (b), connected to another rod electrode with $3 \mathrm{~m}$ copper plate. Configurations (d), (e), and (f), consisted of a grounding device with spike rods (GDSR), with dimensions shown in Table 2 in configuration (d). Configuration (e) consisted of configuration (d) connected to a single rod electrode (a), and configuration (f) with a GDSR, connected to two rod electrodes, with $3 \mathrm{~m}$ copper plate from one rod to another. All of these electrodes were installed $30 \mathrm{~cm}$ below the ground's surface. At site 2, four other electrodes were used, placed $50 \mathrm{~m}$ away from the six configurations installed earlier, with two electrodes in similar configuration to (a) and (d), while the other two configurations (g) consisted of configuration (a) connected to $2 \mathrm{~m} \times 2 \mathrm{~m}$ ground electrode, and configuration (h) consisted of configuration (d) connected to the $2 \mathrm{~m} \times 2 \mathrm{~m}$ ground electrode. The same copper plate, with the width of $2 \mathrm{~cm}$, thickness of $0.2 \mathrm{~mm}$, and length of $3 \mathrm{~m}$ was used in the test to provide connection to the mesh.

The Fall-of-Potential (FoP) method was performed to determine its $\mathrm{R}_{\mathrm{DC}}$ values, which are also presented in Table 2. As seen and expected, the larger the size of the ground electrodes (configurations (c) and (f)), the lower the $R_{D C}$ values were. Though the soil resistivity of the upper layer for site 2 was lower, high $R_{D C}$ values were seen for ground electrodes installed at site $2 \mathrm{a}$, in comparison to site 1 , with the same configurations. This could be due to a shallower depth of site 2, below $2 \mathrm{~m}$, where the electrodes may also be influenced by the higher soil resistivity of the lower layer at site 2 . On the other hand, the electrodes installed at site 1 were only in contact with and influenced by the upper layer of soil resistivity, due to a higher depth of the upper layer of more than $10 \mathrm{~m}$. We also noticed that that the difference in $R_{D C}$ values became smaller in electrodes with low $R_{D C}$ values, i.e., the difference in $R_{D C}$ values of configurations (a) and (d) installed at site $2 \mathrm{~b}$ was more than $30 \%$, while the difference in $R_{D C}$ values between configurations (g) and (h) was less than $15 \%$. This finding was similar to that published in several standards [1,9]; the lower the ground resistance $R_{D C}$ value, the less pronounced the reduction in $R_{D C}$ values expected to be present. Another ground electrode for the neutral pin of the power adapter that was connected to a single rod electrode had $R_{\mathrm{DC}}$ values that were measured as $625 \Omega$ for site 1 and $913 \Omega$ for sites $2 \mathrm{a}$ and $2 \mathrm{~b}$. In the case of a high current that may occur during the test, the ground terminal of the impulse generator was connected to $20 \mathrm{~m} \times 30 \mathrm{~m}$ grid, having an $R_{\mathrm{DC}}$ of $8 \Omega$ to provide the path for any high current that may have occurred during the tests.

Table 2. Configurations of ground electrodes and their corresponding $R_{\mathrm{DC}}$ values.

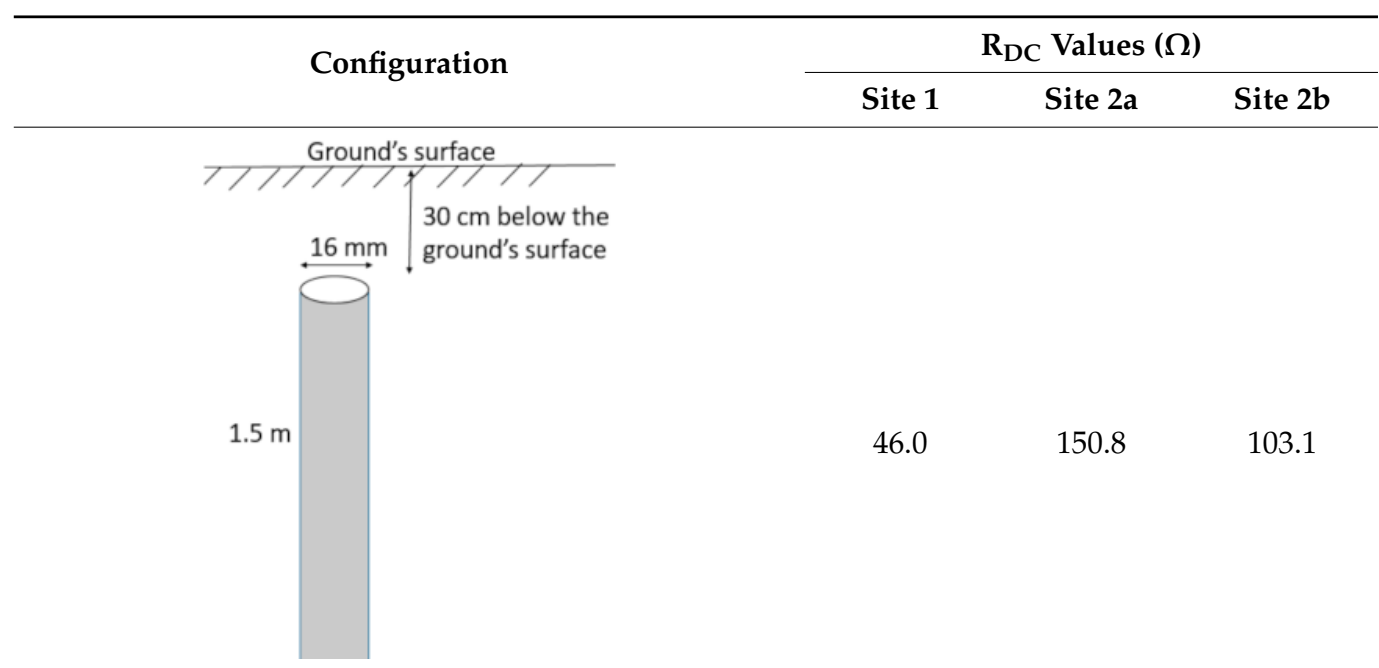

(a) Single rod electrode 
Table 2. Cont.

\begin{tabular}{cccc}
\hline Configuration & \multicolumn{3}{c}{$\mathbf{R}_{\text {DC Values }(\Omega)}$} \\
\cline { 3 - 4 } & Site 1 & Site 2a & \\
\hline $1.5 \mathrm{~m}$ & & \\
\hline
\end{tabular}

(b) 2-rod electrode

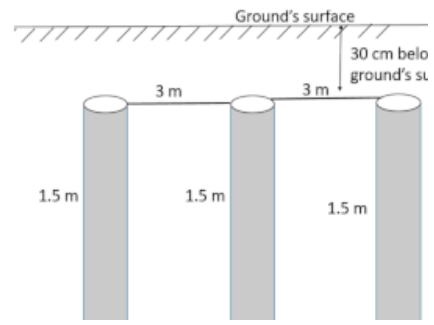

(c) 3-rod electrode

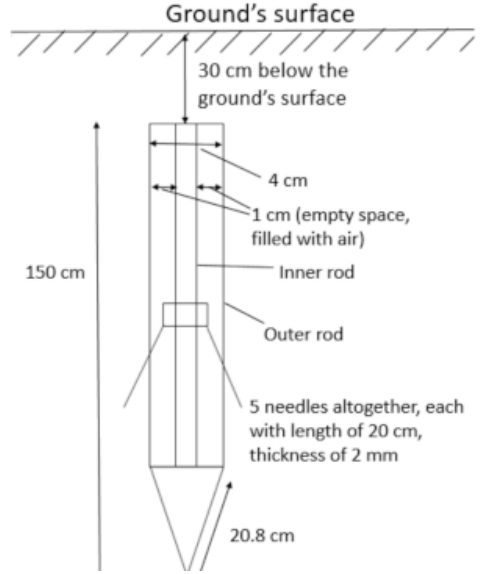

(d) Grounding devices with spike rods (GDSR)

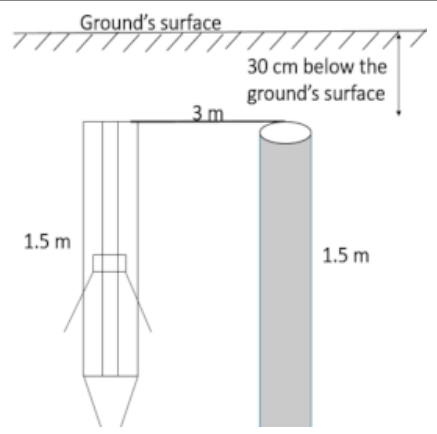


Table 2. Cont.

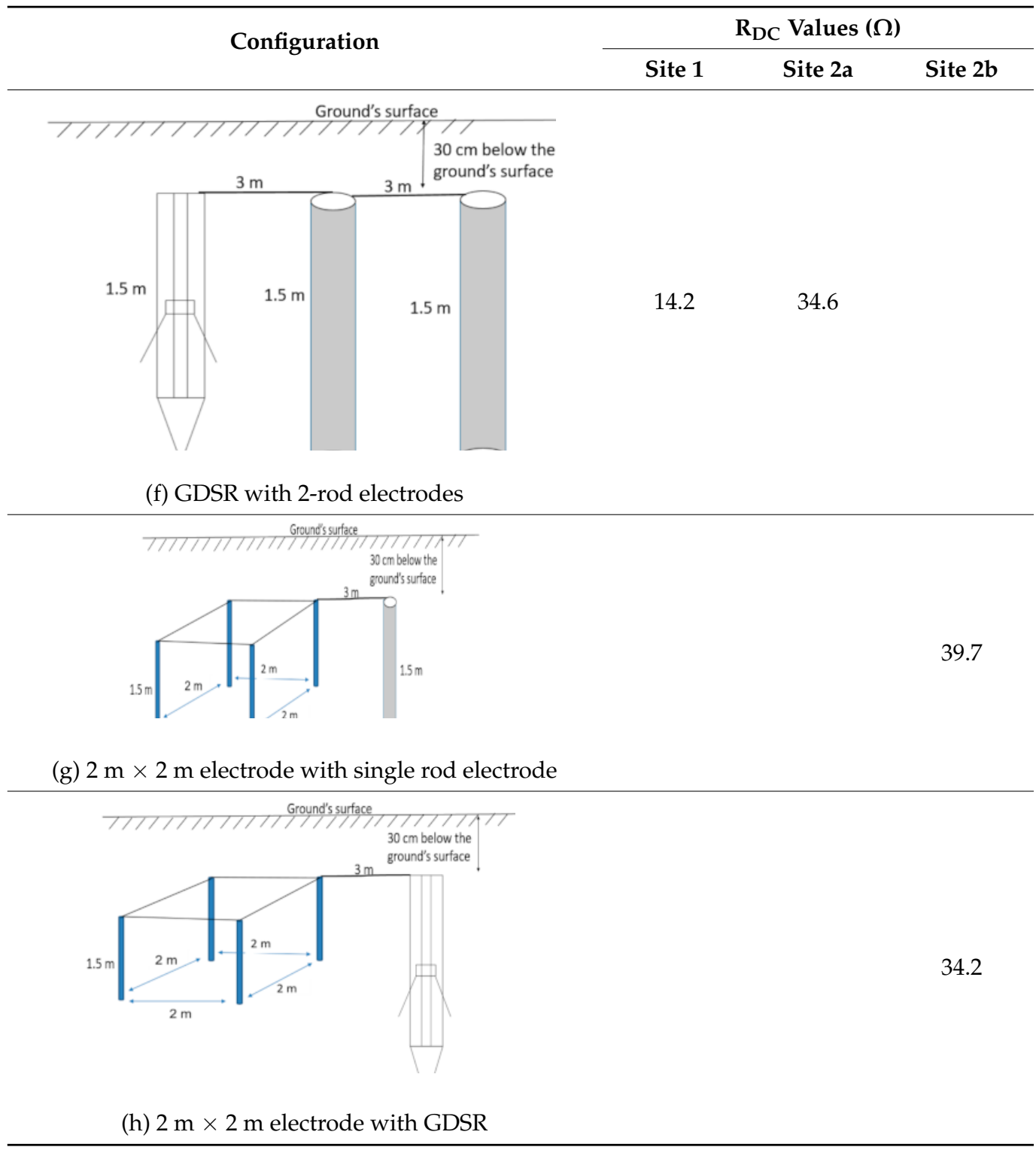

\section{Test Results}

\subsection{Measurements from Voltage Divider 1 and Current Transformer 1}

The measurement from the voltage divider 1 was taken to represent the applied voltage, while the current transformer 1 was the current that flowed to the DP's ground. Figure 2 shows the voltage applied to the DP. As stated in Section 2.1, the voltage applied to the gas surge arrester, while the current trace of Figure 2 was measured as the current that flowed to the ground at the DP, indicated the DP earth of various configurations in Figure 1. Similar traces were seen for other ground electrode configurations and impulse polarity, except for some changes in the magnitudes of voltage and current, depending on the ground electrode's performance. The Figure shows fast rise times of voltage and current traces, and the current signal follows the voltage signal on both front and decay times, indicating a predominantly resistive behavior of the ground electrode. Throughout the course of the test, it was difficult to achieve the desired charging voltage of $30 \mathrm{kV}$ when the tests were performed on configurations (b) and (c) installed at site 1, and configuration (b) installed at site 2 , under negative impulse polarity, despite the fact that several attempts were made. When charging voltage levels were increased under negative impulse polarity on these configurations, higher than $30 \mathrm{kV}$, triggering in the impulse generator was achieved. It is 
thought that the non-achieved charging voltage at $30 \mathrm{kV}$, for negative impulse polarity could be due to a higher voltage to cause a breakdown in the spark gap of the impulse generator under negative impulse polarity, which was a typical observation in the breakdown of the air gap, whereby a higher voltage was needed to cause a breakdown for negative rather than positive impulse polarity, as described in [8]. For other sites, the triggering was achieved at $30 \mathrm{kV}$ under negative impulse polarity, which could be due to probabilistic characteristics of the air breakdown of the spark gap, especially the tests carried out in situ, where uncontrollable atmospheric pressure and surrounding conditions could happen.

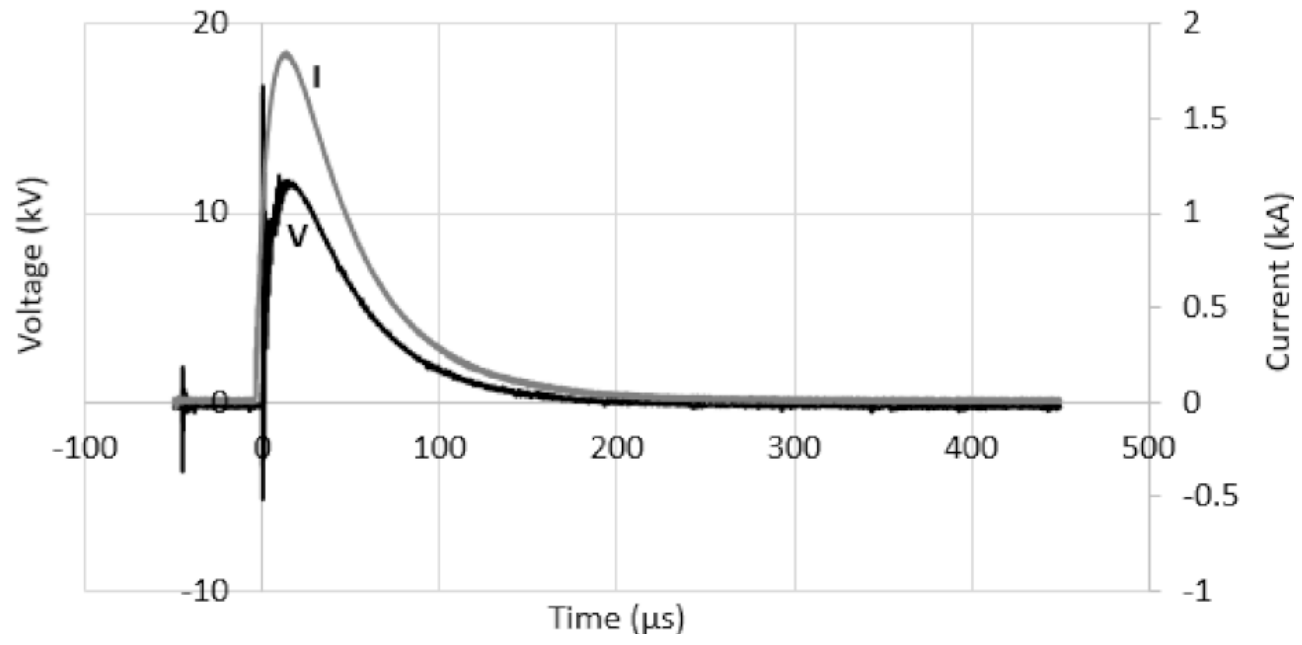

Figure 2. Voltage and current traces, measured with voltage divider 1 and current transformer 1 , respectively, for configuration (f) installed at site 1 .

From the voltage and current plots, impulse impedance values were measured by dividing the peak voltage by the peak current, Vpeak/Ipeak. Table 3 shows the impulse impedance $Z_{\text {imp }}$ values in comparison to their corresponding $R_{D C}$ for each ground electrode and for both impulse polarities. The Table illustrates that the $Z_{i m p}$ values are always lower than that of the corresponding $R_{D C}$ values for both impulse polarities. The percentage difference between the $R_{D C}$ and $Z_{i m p}$ values was measured by taking the difference between $R_{D C}$ and $Z_{i m p}$ and dividing it by $R_{D C}$, and the resultant was multiplied by a hundred percent. We observed that generally the higher the $R_{D C}$, the higher the percentage difference was between $R_{D C}$ and $Z_{i m p}$. This finding is similar to that found in several publications [6,7], Refs.[12,13] whereby the degree of reduction is dependent on the $R_{D C}$ values. This is thought to be due to the dependency of the electric field $E$ on the soil resistivity $\rho$, and the current density $J$, where $J$ is in general a division of current $I$ to the cross-sectional area $A$, as defined in Equation (1). As generally known, the non-linearity in impulse impedance, where a reduction in $R_{D C}$ to impulse impedance $Z_{\text {impulse }}$ would occur if the electric field $E$ were higher than the critical electric field $E_{c}$. For a high $\mathrm{R}_{\mathrm{DC}}$, the ground electrodes may have been installed in high $\rho$, have a low $\mathrm{A}$, or have both conditions, which would cause a rise in the electric field value E, exceeding the Ec. Due to this, a higher rate of non-linearity, which causes a higher percentage of reduction in impulse impedance from $R_{D C}$, would be exhibited for ground electrodes with a high $\mathrm{R}_{\mathrm{DC}}$. Another reason could be due to larger air voids for soil in high soil resistivity in comparison to low soil resistivity where the air voids may have filled up with water, and the soil is more compacted. Hence, more discharges might have occurred in high soil resistivity (high $\mathrm{R}_{\mathrm{DC}}$ ) in comparison to low soil resistivity (low $\mathrm{R}_{\mathrm{DC}}$ ), causing a significant reduction in impulse impedance from its RDC in high soil resistivity (high $\mathrm{RDC}$ ).

In this study, it was established that the percentage difference between $Z_{i m p}$ and $R_{D C}$ was not affected by the impulse polarity

$$
E=\rho J
$$


Table 3. $R_{D C}, Z_{i m p}$, and percentage difference between $R_{D C}$ and $Z_{i m p}$.

\begin{tabular}{|c|c|c|c|c|c|c|c|c|c|c|c|c|c|}
\hline \multirow{3}{*}{ Conf. } & \multicolumn{3}{|c|}{$R_{D C}(\Omega)$} & \multicolumn{5}{|c|}{ Impulse Impedance Values $(\Omega)$} & \multicolumn{5}{|c|}{$\begin{array}{c}\text { Percentage Difference Between } R_{D C} \\
\text { and } Z_{\text {impulse }}(\%)\end{array}$} \\
\hline & \multirow{2}{*}{ Site 1} & \multirow{2}{*}{ Site 2a } & \multirow{2}{*}{ Site $2 b$} & \multirow{2}{*}{$\begin{array}{c}\text { Site } 1 \\
+\end{array}$} & \multicolumn{2}{|c|}{ Site $2 a$} & \multicolumn{2}{|c|}{ Site $2 b$} & \multicolumn{2}{|c|}{ Site 1} & Site 2a & \multicolumn{2}{|c|}{ Site $2 b$} \\
\hline & & & & & - & + & - & + & + & - & + & - & + \\
\hline (a) & 46 & 150.8 & 103.1 & 13.5 & 13.4 & 24.6 & 25.4 & 38.5 & 70.65 & 70.87 & 83.69 & 83.16 & 62.66 \\
\hline (b) & 30.9 & 78.7 & & 8.2 & * & 16.9 & * & & 73.46 & * & 78.53 & * & \\
\hline (c) & 14.3 & 42.2 & & 5.7 & * & 11.1 & 11.5 & & 60.14 & * & 73.7 & 72.75 & \\
\hline (d) & 31.4 & 88.5 & 69.1 & 12.2 & 12.8 & 22.1 & 19.6 & 20.82 & 61.15 & 59.24 & 75.03 & 77.85 & 69.9 \\
\hline (e) & 19.2 & 49.8 & & 8.8 & 8.1 & 15.3 & 14.4 & & 54.17 & 57.81 & 69.28 & 71.08 & \\
\hline (f) & 14.2 & 34.6 & & 6.3 & 6.4 & 10.8 & 10.6 & & 55.63 & 54.93 & 68.79 & 69.36 & \\
\hline (g) & & & 39.7 & & & & & 12.97 & & & & & 67.33 \\
\hline (h) & & & 34.2 & & & & & 15.2 & & & & & 55.56 \\
\hline
\end{tabular}

*Charging voltage at $30 \mathrm{kV}$ is not achieved. $\square$ No damage to the modem is observed.

\subsection{Measurements from Voltage Divider 2 and Current Transformers 2 and 3}

In this study, the voltage divider 2 was used to measure the voltage applied on the modem, while the current transformer 2 was applied to measure the current that flowed through the modem, as shown in Figure $3 a, b$, respectively, for voltage and current traces for configuration (h), installed at site $2 b$ under positive impulse polarity. It can be seen from both Figures that the traces had fast rise times and were found to be rather distorted. These traces were for the condition of no damage to the modem, i.e., the modems were found to be in good working condition after the tests were carried out. On the other hand, higher voltage and current traces were observed for the case of damage to the modems, shown in Figure $4 \mathrm{a}, \mathrm{b}$ for voltage and current traces, respectively. As can be seen in the Figure, a collapse of voltage was seen in Figure 4a with oscillations, which were followed by a slight increase in the current magnitudes, indicated in the corresponding Figure 5a. A sudden voltage drop followed by an increase in current is a typical indication of equipment breakdown when high voltage tests are carried out on it, as discussed in [9]. Oscillations in the voltage trace could be due to harmonics that may be present due to pre-discharges within the test circuit in the modem.

Despite the fact that new modems were used for every test, it was noted that voltage and current traces produced from the voltage divider and current transformer were of many shapes; they were found to be different not only in various ground electrodes, but also in both impulse polarities for the same ground electrodes. This could be due to many components in the modems that affected the way that the currents and voltage went through them, and the damage may have been caused by the failure that occurred in different components from one test to another.

Current transformer 3 measured the current flows through the power adapter, where the typical current trace was shown in Figure 5a,b, respectively, for the case of no damage and damage to the modems. The current traces were, however, found to be different in shape and magnitude for different configurations and impulse polarity; some had current traces that flowed to the ground of the modem that was found to be zero. Table 4 summarises the voltage and current magnitudes of the modem and the condition of the modem post-tests. In correlating the $\mathrm{R}_{\mathrm{DC}}$ values of the ground electrode with the damage to the modem, it can be seen that the damage to the modem occurred in the ground electrode with an $R_{D C}$ value below $30 \Omega$ in high resistivity soil (site 2), while a higher $R_{D C}$ value was seen in low resistivity soil (site $\left.2 a\right)$, and no damage was seen for the ground electrode with an $R_{D C}$ value below $46 \Omega$. 


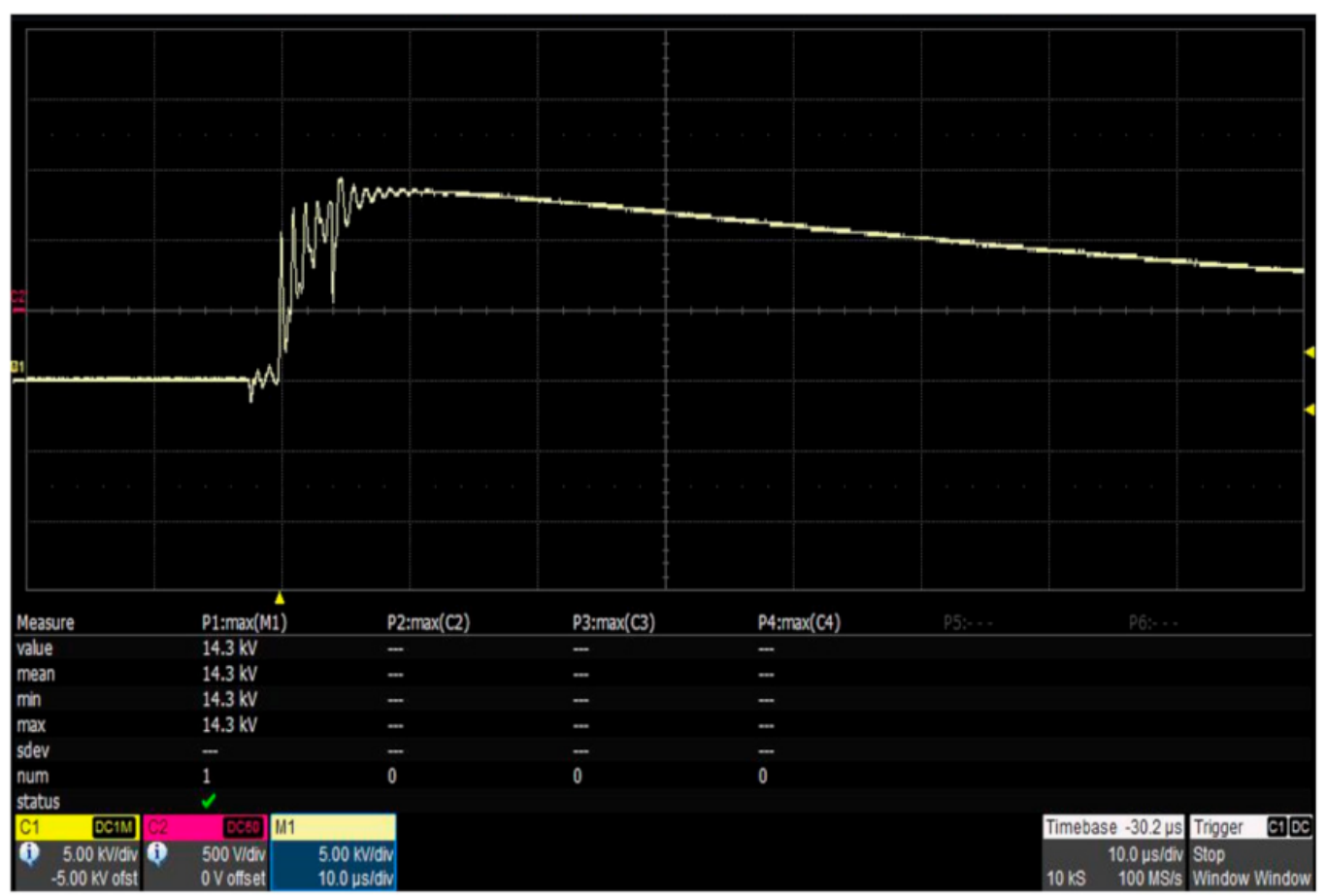

(a)

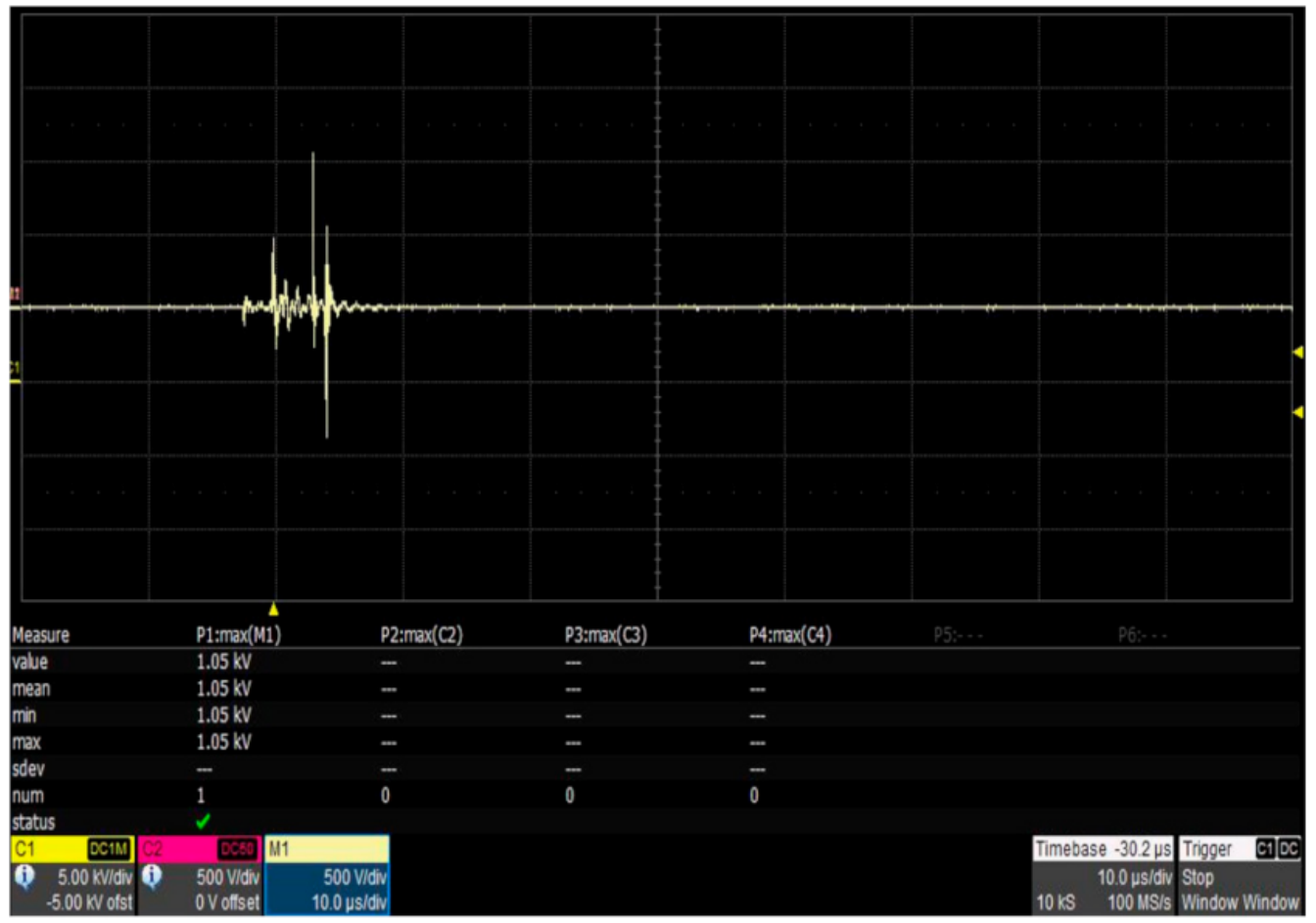

(b)

Figure 3. Measured traces on the modem for the case of no damage to the modem for configuration (h) installed at site $2 \mathrm{~b}$ (a) Voltage trace measured with voltage probe 2 (x scale is $10 \mu \mathrm{s} / \mathrm{div}$, and y scale is $5 \mathrm{kV} / \mathrm{div}$ ); (b) Current flows through the modem, measured with current transformer (CT) 2 ( $x$ scale is $10 \mu \mathrm{s} / \mathrm{div}$, and y scale is $5 \mathrm{kV} / \mathrm{div}$, and the voltage magnitude is multiplied by 10 , since the CT used had a sensitivity of $0.1 \mathrm{~V} / \mathrm{A}$ ). 


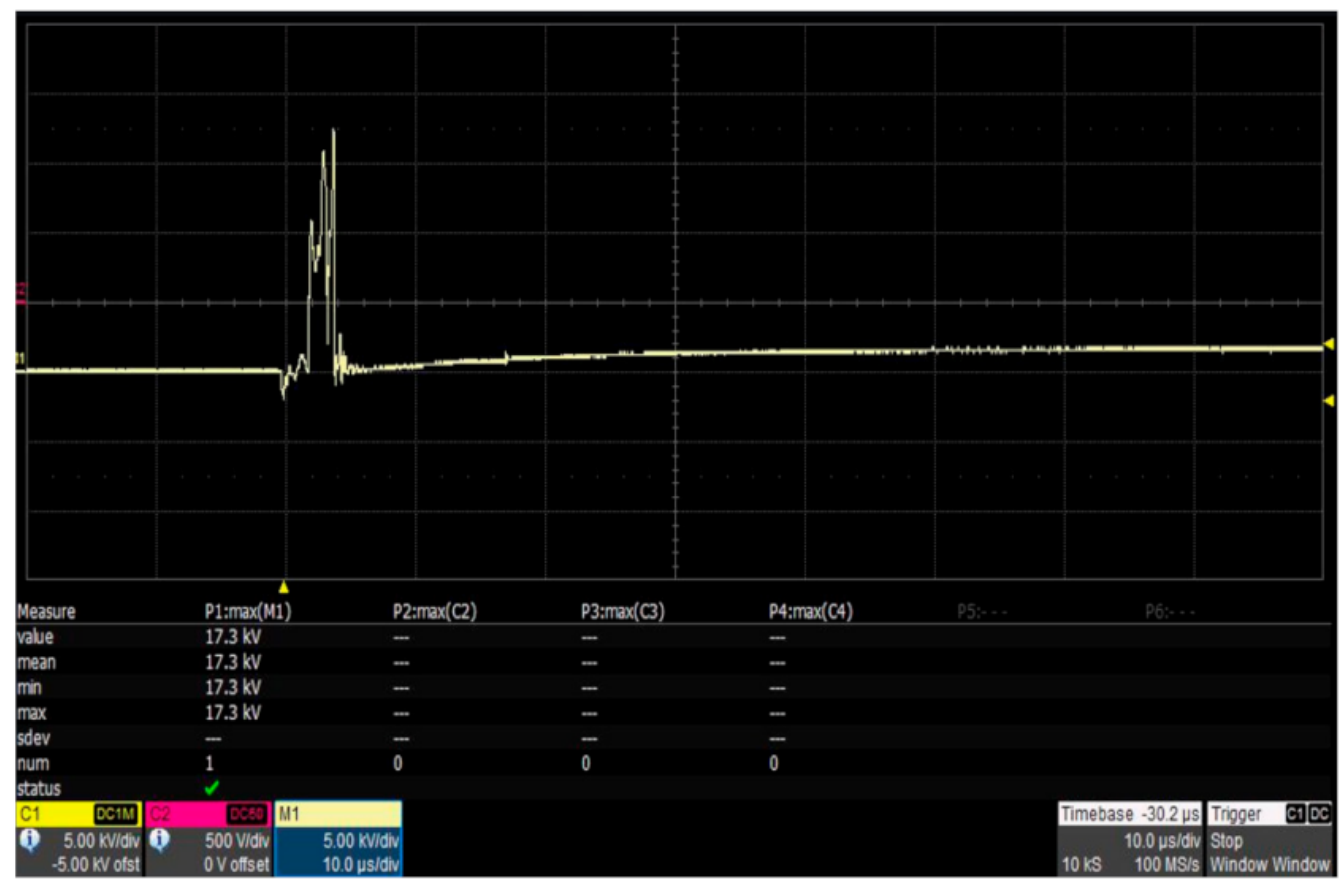

(a)

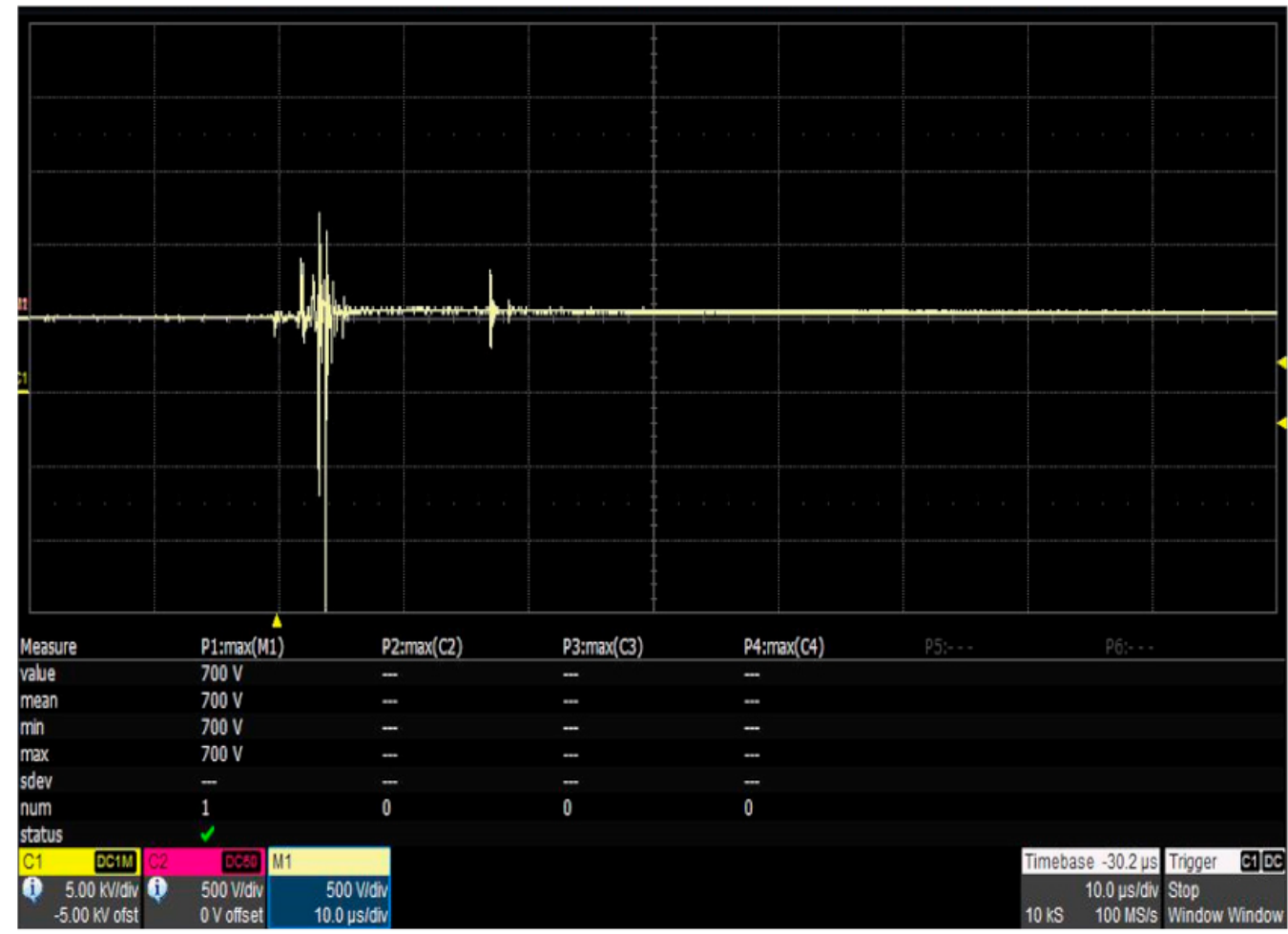

(b)

Figure 4. Measured traces on the modem for the case of damage to the modem for configuration (d), installed at site $2 \mathrm{~b}$ (a) Voltage trace measured with voltage divider 2 (x scale is $10 \mu \mathrm{s} / \mathrm{div}$, and y scale is $5 \mathrm{kV} / \mathrm{div}$ ); (b) Current flows through the modem, measured with current transformer (CT) 2 ( $x$ scale is $10 \mu \mathrm{s} / \mathrm{div}$, and y scale is $5 \mathrm{kV} / \mathrm{div}$, and the voltage magnitude is multiplied by 10 , since the CT used had a sensitivity of $0.1 \mathrm{~V} / \mathrm{A}$ ). 


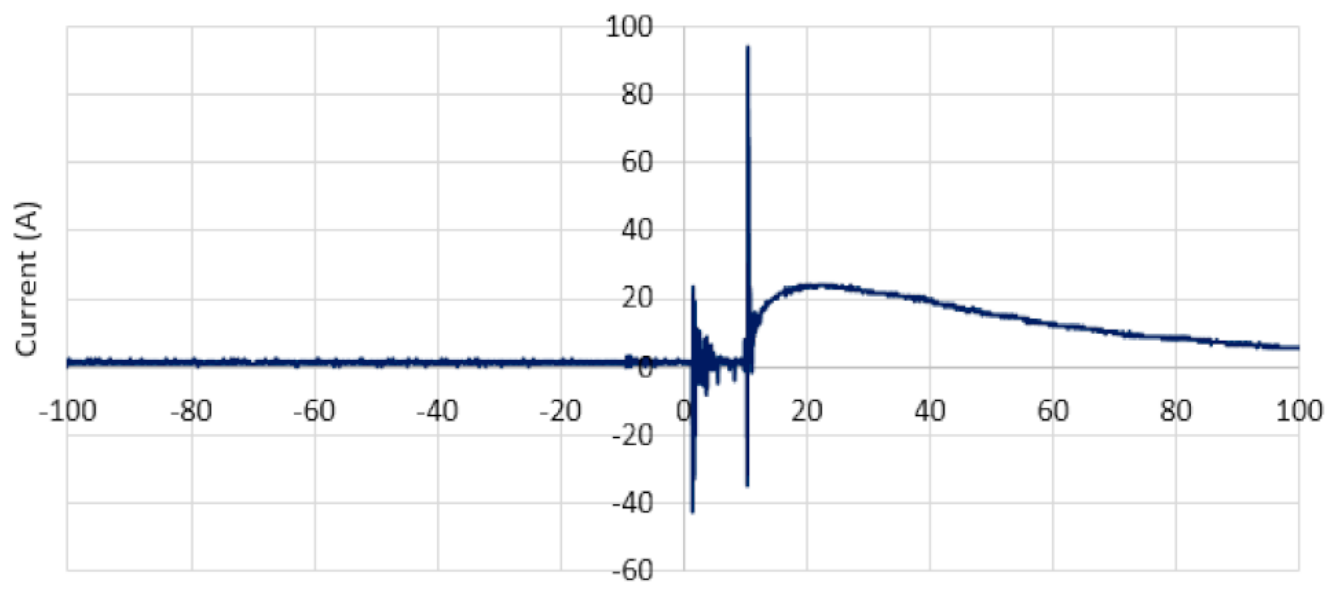

Time $(\mu s)$

(a)

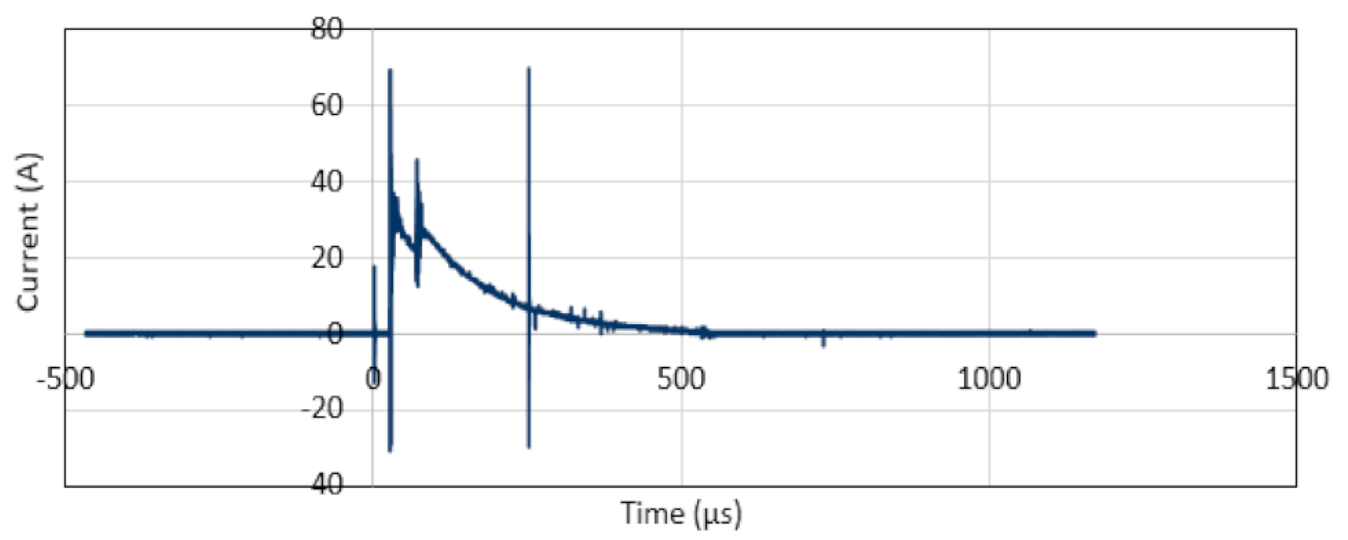

(b)

Figure 5. Current flows through the power adapter, measured with current transformer (CT) 3 (a) Configuration (b) installed at site 1, for the case of no damage to the modem; (b) Configuration (a) installed at site 2 , for the case of damage to the modem.

We also noticed no damage to the modem if any of the three conditions were fulfilled: (i) voltage at the modem was below $15 \mathrm{kV}$, and the current magnitude was below $35 \mathrm{~A}$; (ii) voltage at the modem was higher than $15 \mathrm{kV}$ (i.e., configuration (f) installed at site 1), but the current was below $5 \mathrm{~A}$; and (iii) higher current magnitudes, more than $35 \mathrm{~A}$ (i.e., configuration (f) installed at site $2 \mathrm{~b}$ ), the voltage at the modem must be low enough, no more than $2 \mathrm{kV}$. Other than these three conditions, damage to the modems was present. We also detected no observable factor in terms of impulse polarity. Despite the fact that only one modem was tested for each test, and the damage to the modem could be probabilistic, it was still clear that more modems experienced damage to the ground electrodes installed at sites $2 \mathrm{a}, \mathrm{b}$, which had higher $\mathrm{R}_{\mathrm{DC}}$ values than that in site 1 . Higher magnitudes of current were noticed flowing through the modem, reaching hundreds of amperes in some modems. High current magnitudes were also seen going through the power adapter, which can pose a danger to the modem users. This shows the importance of considering ground electrodes with low $\mathrm{R}_{\mathrm{DC}}$ values at the distribution pole, at the customer's premises, or utility to avoid any modem damage on site. 
Table 4. Voltage and current magnitudes and the condition of the modem for various ground electrodes.

\begin{tabular}{|c|c|c|c|c|c|c|}
\hline $\begin{array}{l}\text { Site/ Conf./R } \\
\text { Values }\end{array}$ & $\begin{array}{l}\text { Impulse } \\
\text { Polarity }\end{array}$ & $\begin{array}{l}\text { Voltage on } \\
\text { the Modem, } \\
\text { V2 }(\mathrm{kV})\end{array}$ & $\begin{array}{l}\text { Current through } \\
\text { the Modem, } \\
\text { CT2 (A) }\end{array}$ & $\begin{array}{l}\text { Condition of } \\
\text { the Modem } \\
\text { after the Tests }\end{array}$ & $\begin{array}{l}\text { Current on the } \\
\text { Power Adapter, } \\
\text { CT3 (A) }\end{array}$ & Condition Fulfilment \\
\hline \multirow[b]{2}{*}{ Site 1 (a), $46 \Omega$} & Positive & 8 & 28 & Working & 26.4 & \multirow{2}{*}{$\begin{array}{l}\text { Fulfilling condition (i) voltage at the } \\
\text { modem is below } 15 \mathrm{kV} \text {, and the } \\
\text { current magnitudes is below } 35 \mathrm{~A} \text {. } \\
\text { Fulfilling condition (i) voltage at the } \\
\text { modem is below } 15 \mathrm{kV} \text {, and the } \\
\text { current magnitudes is below } 35 \mathrm{~A} \text {. }\end{array}$} \\
\hline & Negative & -8 & -33.6 & Working & -34.4 & \\
\hline \multirow[t]{2}{*}{ Site $1(b), 30.9 \Omega$} & Positive & 14.8 & \multirow[t]{2}{*}{20} & Working & 22.4 & \multirow[t]{2}{*}{$\begin{array}{l}\text { Fulfilling condition (i) voltage at the } \\
\text { modem is below } 15 \mathrm{kV} \text {, and the } \\
\text { current magnitudes is below } 35 \mathrm{~A}\end{array}$} \\
\hline & Negative & \multicolumn{3}{|c|}{ No triggering achieved at $30 \mathrm{kV}$} & & \\
\hline \multirow[t]{2}{*}{ Site 1 (c), $14.3 \Omega$} & Positive & 13 & 20 & Working & 0 & $\begin{array}{l}\text { Fulfilling condition (i) voltage at the } \\
\text { modem is below } 15 \mathrm{kV} \text {, and the } \\
\text { current magnitudes is below } 35 \mathrm{~A} \text {. }\end{array}$ \\
\hline & Negative & \multicolumn{5}{|c|}{ No triggering achieved at $30 \mathrm{kV}$} \\
\hline \multirow[b]{2}{*}{ Site $1(\mathrm{~d}), 31.4 \Omega$} & Positive & 4 & 60 & Damaged & 24.4 & $\begin{array}{l}\text { Not fulfilling any of the } \\
\text { three conditions }\end{array}$ \\
\hline & Negative & -16.4 & -62.4 & Damaged & -28.4 & $\begin{array}{l}\text { Not fulfilling any of the } \\
\text { three conditions }\end{array}$ \\
\hline \multirow{2}{*}{ Site $1(\mathrm{e}), 19.2 \Omega$} & Positive & 13.2 & 1.6 & Working & 0 & \multirow{2}{*}{$\begin{array}{l}\text { Fulfilling condition (i) voltage at the } \\
\text { modem is below } 15 \mathrm{kV} \text {, and the } \\
\text { current magnitudes is below } 35 \mathrm{~A} \text {. } \\
\text { Fulfilling condition (i) voltage at the } \\
\text { modem is below } 15 \mathrm{kV} \text {, and the } \\
\text { current magnitudes is below } 35 \mathrm{~A} \text {. }\end{array}$} \\
\hline & Negative & -13.2 & -23.2 & Working & -25.2 & \\
\hline \multirow{2}{*}{ Site $1(\mathrm{f}), 14.2 \Omega$} & Positive & 12 & 1.6 & Working & 0 & \multirow{2}{*}{$\begin{array}{l}\text { Fulfilling condition (i) voltage at the } \\
\text { modem is below } 15 \mathrm{kV} \text {, and the } \\
\text { current magnitudes is below } 35 \mathrm{~A} \text {. } \\
\text { (ii) voltage on the modem is higher } \\
\text { than } 15 \mathrm{kV} \text {, but the current is below } 5 \mathrm{~A} \text {. }\end{array}$} \\
\hline & Negative & -16 & -3.6 & Working & 0 & \\
\hline \multirow{2}{*}{ Site $2 \mathrm{a}(\mathrm{a}), 150.8 \Omega$} & Positive & 6.2 & 244 & Damaged & 30 & \multirow{2}{*}{$\begin{array}{l}\text { Not fulfilling any of the } \\
\text { three conditions } \\
\text { Not fulfilling any of the } \\
\text { three conditions }\end{array}$} \\
\hline & Negative & -7.2 & -236 & Damaged & -38 & \\
\hline \multirow{2}{*}{ Site $2 \mathrm{a}(\mathrm{b}), 78.7 \Omega$} & Positive & 15 & 3640 & Damaged & 0 & $\begin{array}{l}\text { Not fulfilling any of the } \\
\text { three conditions }\end{array}$ \\
\hline & Negative & \multicolumn{5}{|c|}{ No triggering achieved at $30 \mathrm{kV}$} \\
\hline \multirow{2}{*}{ Site $2 \mathrm{a}(\mathrm{c}), 42.2 \Omega$} & Positive & 12 & 23 & Working & 23 & \multirow{2}{*}{$\begin{array}{l}\text { Fulfilling condition (i) voltage at the } \\
\text { modem is below } 15 \mathrm{kV} \text {, and the } \\
\text { current magnitudes is below } 35 \mathrm{~A} \text {. } \\
\text { Fulfilling condition (i) voltage at the } \\
\text { modem is below } 15 \mathrm{kV} \text {, and the } \\
\text { current magnitudes is below } 35 \mathrm{~A} \text {. }\end{array}$} \\
\hline & Negative & -14.4 & -22.4 & Working & 0 & \\
\hline \multirow{2}{*}{ Site $2 \mathrm{a}(\mathrm{d}), 88.5 \Omega$} & Positive & 5 & 200 & Damaged & 25 & \multirow{2}{*}{$\begin{array}{l}\text { Not fulfilling any of the } \\
\text { three conditions } \\
\text { Not fulfilling any of the } \\
\text { three conditions }\end{array}$} \\
\hline & Negative & -16 & -40 & Damaged & -42 & \\
\hline \multirow[b]{2}{*}{ Site $2 \mathrm{a}(\mathrm{e}), 49.8 \Omega$} & Positive & 14 & 220 & Damaged & 28 & \multirow{2}{*}{$\begin{array}{l}\text { Not fulfilling any of the } \\
\text { three conditions } \\
\text { Not fulfilling any of the } \\
\text { three conditions }\end{array}$} \\
\hline & Negative & -14 & -308 & Damaged & -28 & \\
\hline \multirow[b]{2}{*}{ Site $2 a(f), 34.6 \Omega$} & Positive & 5 & 80 & Damaged & 20 & \multirow{2}{*}{$\begin{array}{c}\text { Not fulfilling any of the } \\
\text { three conditions } \\
\text { Fulfilling condition (iii) higher } \\
\text { current magnitudes, more than } 35 \mathrm{~A} \text {, } \\
\text { but the voltage at the modem is not } \\
\text { more than } 2 \mathrm{kV}\end{array}$} \\
\hline & Negative & -2 & -126.4 & Working & -26 & \\
\hline Site $2 b(a), 103.1 \Omega$ & Positive & 17.2 & 0 & Damaged & Not measured & $\begin{array}{l}\text { Not fulfilling any of the } \\
\text { three conditions }\end{array}$ \\
\hline Site $2 b(d), 69.1 \Omega$ & Positive & 17.3 & 0 & Damaged & Not measured & $\begin{array}{l}\text { Not fulfilling any of the } \\
\text { three conditions }\end{array}$ \\
\hline Site $2 \mathrm{~b}(\mathrm{~g}), 39.7 \Omega$ & Positive & 16.7 & 0 & Damaged & Not measured & $\begin{array}{l}\text { Not fulfilling any of the } \\
\text { three conditions }\end{array}$ \\
\hline Site $2 b(h), 34.2 \Omega$ & Positive & 14.3 & 0 & Working & Not measured & $\begin{array}{l}\text { Fulfilling condition (i) voltage at the } \\
\text { modem is below } 15 \mathrm{kV} \text {, and the } \\
\text { current magnitudes is below } 35 \mathrm{~A} \text {. }\end{array}$ \\
\hline
\end{tabular}




\section{Conclusions}

An investigation of the damage to a modem with a different $R_{D C}$ was conducted at a charging voltage of $30 \mathrm{kV}$. There was no specific trend found on the dependency of the damage to the modem in terms of impulse polarity. This is thought to be due to the low voltage level used, which was only $30 \mathrm{kV}$ and made the impulse polarity effect not that observable. When impulse tests with a voltage level of $30 \mathrm{kV}$ were carried out on 16 ground electrodes connected to the distribution poles, modems, and adapters, we noticed that no damage occurred on the modem in the event of any of these three observations: (i) voltage at the modem was less than $15 \mathrm{kV}$, and the current that flowed through it was less than $35 \mathrm{~A}$; (ii) voltage on the modem was higher than $15 \mathrm{kV}$, but the current was below $5 \mathrm{~A}$; and (iii) for the case of a high current at the modem, the voltage had to be low enough, below $2 \mathrm{kV}$. We also observed that the current that flowed through the power adapter could reach more than $20 \mathrm{~A}$, which in real application and practice, can cause tripping in the premises and pose a danger to the users. We expected it to be difficult to consider these three conditions for damage to the modems and safety considerations for the users, since testing and taking high voltage measurements are not common. For this reason, the basis of the adequacy of the grounding system at the premises is evident in this paper. In order to avoid damage to the modems and provide safety to current-sensitive equipment at the premises, it is important to consider having the grounding systems at the DP below $30 \Omega$ in general and lower than $46 \Omega$ if the ground electrode is installed and in contact with soil with a low resistivity value below $100 \Omega \mathrm{m}$. This study is anticipated to raise awareness to users and telecommunication companies and even more so toward the design innovation of modem susceptibility, with the grounding systems at the DP in mind and at the customers' premises. High magnitudes of current were observed at the modem, and the power adapter provided valuable information to the users and was useful in improving the ground resistance value and avoiding contact with modems during severe weather conditions. Furthermore, this study presents an integral suggestion that surge protective devices should be used alongside modems and other current-sensitive devices at the premises in order to avoid functional and structural damage to the CPE.

Author Contributions: Conceptualization, N.M.N. and A.M.R.; methodology, N.M.N. and A.M.R.; validation, N.M.N. and A.M.R.; formal analysis, N.M.N.; investigation, N.M.N. and A.M.R.; resources, N.N.A.; data curation, U.M.; writing—original draft preparation, U.M.; writing—review and editing, N.M.N.; visualization, N.M.N.; supervision, N.M.N. and N.N.A.; project administration N.M.N. and N.N.A.; funding acquisition, N.M.N. and N.N.A. All authors have read and agreed to the published version of the manuscript.

Funding: This research was funded by TELEKOM MALAYSIA RESEARCH AND DEVELOPMENT (TMR\&D) with the grant numbers MMUE190085 and MMUE210072 and the MINISTRY OF HIGHER EDUCATION (MOHE) on the Fundamental Research Grant Scheme (FRGS) with the grant number FRGS/1/2021/TK0/MMU/02/8.

Institutional Review Board Statement: Not applicable.

Informed Consent Statement: Not applicable.

Data Availability Statement: Not applicable.

Conflicts of Interest: The authors declare no conflict of interest.

\section{References}

1. IEEE. IEEE Guide for Safety in AC Substation Grounding; Std 80-2013; IEEE: Piscataway, NJ, USA, 2013.

2. International Telecommunication Union (ITU) Standard. SERIES K: Protection of Customer Premises from Overvoltages; K. 66; ITU-T: Geneva, Switzerland, 2019.

3. Hidaka, T.; Ishimoto, K.; Asakawa, A.; Shiota, K. Relationship between Grounding Resistance Connected to Surge Arresters and Lightning Surge Behavior Observed in Low-Voltage Equipment. In Proceedings of the International Symposium on Lightning Protection (XII SIPDA), Belo Horizonte, Brazil, 7-11 October 2013. 
4. ITU-T. Series K: Protection Against Interference, Resistibility of Telecommunication Equipment Installed in Customer Premises to Overvoltages and Overcurrents; K.21; ITU-T: Geneva, Switzerland, 2019.

5. Ramli, A.; Jamlus, N.; Ibrahim, A.; Amiruddin, F. Resistive Coupling Effect to Customer Premises Equipment (CPE) due to Non-Equipotential Earthing System. In Proceedings of the IEEE International Conference on High Voltage Engineering and Application (ICHVE), Athens, Greece, 10-13 September 2018.

6. Abdul Ali, A.; Ahmad, N.; Mohamad Nor, N.; Reffin, M.; Syed Abdullah, S. Investigations on the Performance of a New Grounding Device with Spike Rods under High Magnitude Current Conditions. Energies 2019, 12, 1138. [CrossRef]

7. Abdul Ali, A.; Ahmad, N.; Mohamad Nor, N. Effect of Impulse Polarity on a New Grounding Device with Spike Rods (GDSR). Energies 2020, 13, 4672. [CrossRef]

8. Lundgaard, L.; Linhjell, D.; Berg, G. Propagation of Positive and Negative Streamers in Oil with and without Pressboard Interfaces. IEEE Trans. Dielectr. Electr. Insul. 1998, 5, 388-395. [CrossRef]

9. Kuffel, E.; Zaengl, W.S.; Kuffel, J. High Voltage Engineering: Fundamentals; Butterworth-Heinemann: New Delhi, India, 2000.

10. ANSI/TIA/EIA 568-B: Commercial Building Telecommunications Cabling Standard; Cablingdb: Hochiminh City, Vietnam, 2015.

11. BS7430-2011: Code of Practice for Protective Earthing of Electrical Installations; British Standards Institution: London, UK, 2011.

12. Sekioka, S. Frequency and Current-Dependent Grounding Resistance Model for Lightning Surge Analysis. IEEE Trans. Electromagn. Compat. 2018, 61, 419-425. [CrossRef]

13. Harid, N.; Griffiths, H.; Mousa, S.; Clark, D.; Robson, S.; Haddad, A. On the Analysis of Impulse Test Results on Grounding Systems. IEEE Trans. Ind. Appl. 2015, 51, 5324-5334. [CrossRef] 